\title{
BMJ Open Inequalities in complete childhood immunisation in Nepal: results from a population-based cross-sectional study
}

\author{
In Han Song (D) , ${ }^{1,2}$ Elizabeth Palley, ${ }^{3}$ Madhu Sudhan Atteraya ${ }^{4}$
}

To cite: Song $\mathrm{IH}$, Palley $\mathrm{E}$, Atteraya MS. Inequalities in complete childhood immunisation in Nepal: results from a population-based crosssectional study. BMJ Open 2020;10:e037646. doi:10.1136/ bmjopen-2020-037646

- Prepublication history for this paper is available online. To view these files, please visit the journal online (http://dx.doi org/10.1136/bmjopen-2020037646).

Received 12 February 2020 Revised 05 August 2020 Accepted 18 August 2020

\section{Check for updates}

\section{Author(s) (or their} employer(s)) 2020. Re-use permitted under CC BY-NC. No commercial re-use. See rights and permissions. Published by BMJ.

${ }^{1}$ Graduate School of Social Welfare, Yonsei University, Seoul, The Republic of Korea ${ }^{2}$ Department of Health Policy \& Management, Harvard T.H. Chan School of Public Health, Boston, Massachusetts, USA

${ }^{3}$ School of Social Work, Adelphi University, Garden City, New York, USA

${ }^{4}$ Department of Social Welfare, Keimyung University, Daegu, The Republic of Korea

Correspondence to Professor In Han Song; isong@yonsei.ac.kr

\section{ABSTRACT}

Objective To investigate the effect of different aspects of inequality on childhood immunisation rates in Nepal. The study hypothesised that social inequality factors (eg, gender of a child, age of mother, caste/ethnic affiliation, mother's socioeconomic status, place of residence and other structural barrier factors such as living in extreme poverty and distance to health facility) affect the likelihood of children being immunised.

Design Using gender of a child, age of mother, caste/ ethnic affiliation, mother's socioeconomic status, place of residence and other structural barrier factors such as living in extreme poverty and distance to health facility as independent variables, we performed bivariate and multivariate logistic regression analyses.

Setting This study used data from the most recent nationally representative cross-sectional Nepal Demographic and Health Survey in 2016.

Participants The analysis reviewed data from 1025 children aged 12-23 months old.

Outcome measures The main outcome variable was childhood immunisation.

Results Only $79.2 \%$ of children were fully immunised. The complete vaccination rate of ethnic/caste subpopulations ranged from $66.4 \%$ to $85.2 \%$. Similarly, multivariate analysis revealed that children from the previously untouchable caste (OR 0.58; $\mathrm{Cl} 0.33$ to 0.99 ) and the Terai caste (OR 0.54 ; $\mathrm{Cl} 0.29$ to 0.99 ) were less likely to be fully immunised than children from the high Hindu caste. Conclusion Given Nepal's limited resources, we suggest that programmes that target the families of children who are least likely to be fully immunised, specifically those who are not only poor but also in financial crises and 'underprivileged' caste families, might be an effective strategy to improve Nepal's childhood immunisation rates.

\section{INTRODUCTION}

Full immunisation coverage is one of the important agendas for sustainable development goal 3 (SDG 3). However, almost 20 million children under 5 are still not be fully immunised. This is a particular problem in low-income nations such as Nepal. ${ }^{1}$ Full immunisation for young children is an instrumental variable for child health and well-being, which helps reduce infant and child morbidity and mortality rates as well as prevents the spread of infectious diseases. $^{23}$

\section{Strengths and limitations of this study}

- One of the strengths of the study is that it used a nationally representative sample incorporating all sections of socioeconomic, demographic and geographic characteristics, and therefore, the findings are robust and generalisable nationwide.

- Another strength of the study is that the results are useful to help inform national policies for childhood immunisation in Nepal.

- One limitation is the use of cross-sectional data and rely on the validity of the mother's answers to questions about vaccine utilisation since some mothers may have been unaware of different doses of vaccines that their children received.

- Another limitation is that the study excluded data on children who may have been vaccinated when they were over 23 months old

- Next limitation could be communication issues between parents and healthcare service providers in the survey as well as personal and cultural barriers that affect the collection of the data.

Based on WHO protocols, children are considered to be fully immunised or have complete immunisation after receiving a dose of Bacillus Calmette-Guerin (BCG), three doses of diphtheria-tetanus-pertussis (DPT), three doses of oral polio and a dose of Measles, Mumps, and Rubella (MMR) vaccination to protect them from mumps, measles, rubella, polio and tetanus. ${ }^{4}$ Due to international childhood immunisation efforts, infant and child mortality rates have fallen throughout the world including in sub-Saharan Africa and South Asia. ${ }^{5}$ However, within targeted countries, including Nepal, immunisation rates and child mortality rates are unevenly distributed across subpopulations. ${ }^{3}$ In this study, we sought to understand the specific challenges and the factors that impede or facilitate childhood immunisation in Nepal.

Previous research has indicated that social exclusion affects access to healthcare, exacerbates health inequality and reduces healthcare service utilisation. ${ }^{236-10}$ Previous research 
on childhood immunisation coverage in South Asia has examined the effect of a child's gender, his/her family's level of wealth and education, regional inequalities, parental knowledge and attitudes about immunisation and issues related to mother's empowerment. In South Asia, numerous studies have demonstrated that individual factors (a child's gender), family factors (area of residence, household wealth and parental education), demographic factors (religion and caste affiliation) and societal factors (healthcare access and community literacy level) are associated with child immunisation rates. ${ }^{2} 36-10$ The majority of immunisation studies in India has relied on surveys conducted by the National Family Health Survey between 1992/1993 and 2006 suggested that girls were less likely to be immunised than boys. ${ }^{11-13}$ Studies also reported that children were more likely to be immunised if their parents had more knowledge about immunisation, their mothers had more education, they were raised in an urban setting, and their families had more money. ${ }^{14} 15$

In Nepal, the majority of research on immunisation has emphasised evaluating factors that affect access to healthcare as well as the quality of service delivery, including the vaccination rates. ${ }^{6}$ Previous research in Nepal has found that poverty, geographic location (difficult terrain), being from a low caste or indigenous population, traditional cultural attitudes, being woman and low levels of maternal education all reduce the likelihood that a child will be immunised. ${ }^{26710}$ Previous research $^{6}$ found that children from indigenous and previously untouchable caste (eg, Dalits) were less likely to be immunised than high caste children. Terai caste and Muslim children were not included in the study analysis. Indeed, Terai caste and Terai Muslims are the most underprivileged and under representative communities in the Nepalese social structure. ${ }^{16}{ }^{17}$ In an attempt to build on this research and understand current challenges to immunisation in Nepal, this study not only explored demographic information and many of the factors considered above but also examined structural barrier factors that do not exist outside of Nepal. The aim of the study is to examine whether a child's gender, maternal age, caste/ ethnic affiliation, mother's socioeconomic status, place of residence, extreme poverty and distance to health facilities affect the likelihood of a child being immunised in Nepal.

\section{METHODS}

\section{Data}

We used data from the 2016 Nepal Demographic Health Survey (NDHS), a nationally representative sample of Nepal. The data were collected by the Monitoring and Evaluation to Assess and Use Results Demographic and Health Surveys (MEASURE DHS) project. ${ }^{16}$ The DHS project has collected the most comprehensive health data available in developing countries, including Nepal. The data are publicly available through the Ministry of Health and Population of Nepal, New Era Kathmandu and ICF International, USA. The survey is conducted every 5 years with support from the US Agency for International Development through its mission in Nepal and was supported by the Ministry of Health and Population of Nepal. We used data from the Children's Data Section (ie, Child Recode File) of the 2016 NDHS. The data provide health information on every child who was born in the 5 years preceding the survey. The survey also provides information about children who received specific vaccine based on vaccination card and/or mother's report. We only analysed data for children from 12 to 23 months $(\mathrm{n}=1025)$. We selected this data because most children are completely immunised by the age of 24 months. ${ }^{18}$

\section{Dependent variable}

As per the WHO recommendation, a child was considered to be fully immunised if $s /$ he received a BCG vaccine at birth or soon after; three doses each of DPT and polio vaccine at 6,10 and 14 weeks of age; and the measles vaccine at 9 months or soon thereafter. ${ }^{19}$ We aggregated the values of a BCG vaccine, three DPT and polio vaccines and a dose of measles. A value of ' 1 ' was assigned for children who received all three vaccines and was considered to be fully immunised; children who were either unvaccinated or only partially vaccinated were grouped together and coded as ' 0 '. Similarly, those children who received complete doses of DPT and polio vaccines were coded as 1 and those who were unvaccinated or only partially vaccinated for DPT and polio were coded as ' 0 .' Those who received a measles vaccine were coded as 1 and all other values were coded as 0 . In further analysis, we did not consider BGG vaccination because almost $98 \%$ children were BCG vaccinated.

\section{Independent variable coding}

The individual level covariates included gender of the child, age of the mother, mother's educational attainment, family wealth index, mother's age and number of living children under the age of 5 . These demographic, biological and socioeconomic characteristics were based on factors that had been previously shown to be associated with childhood immunisation. ${ }^{3} 6811141520$ We included Nepali-specific contextual factors such as caste/ethnic affiliation, ecological and regional location of residence (urban/rural and provinces). Other variables (eg, structural barrier factors for healthcare service utilisation) we considered were distance to a health facility and immediate financial situation (eg, money as a big problem to visit healthcare service and distance to healthcare facility).

All independent variables in the study were categorical variable, except the number of children under the age of 5 . A boy was coded as ' 1 ' and a girl was coded as ' 2 '. The NDHS provides mother age groups in 5-year interval (15-49). We recoded creating a mother's age group into four categories as 15-19, 20-29, 30-39 and $40-49$.

There are 125 registered caste/ethnic groups in Nepal and one's caste/ethnicity is determined by birth. Within such heterogeneity of caste/ethnic groupings, the NDHS provides 11 different categories of caste/ethnicity affiliation, which we further grouped into four categories based on previous studies ${ }^{21}$ as high Hindu caste, previously 
untouchable caste (eg, Dalits), indigenous (Newars and Janajati) and other Terai caste (ie, Madeshi and Muslims). The NDHS provides mother's educational attainment as illiterate, primary school attainment, secondary school attainment and higher education attainment. We recoded again and coded as ' 0 ' for those mother who have never attended any schooling, ' 1 ' for primary education completion and ' 2 ' was coded for secondary and higher education attainment. The NDHS provides five categories of wealth index based on household's cumulative living standard and it was recoded as poorest, poor, middle, rich and richest.

Nepal has three distinct geographical regions (Mountain, Hill and Terai) and we coded geographical regions into three categories. The Mountain region includes areas with elevation of 3000 metres above sea level to Mount Everest (elevation $8848 \mathrm{~m}$ ), the tallest Mountain in the world. The Hill region lies between elevations of 700 and $3000 \mathrm{~m}$ above sea level, and the Terai region is relatively flat and borders of India. Similarly, cities and towns were grouped into urban area that were coded as ' 1 '; villages were grouped under the rural area that were coded as ' 2 '.

In 2015, according to the Constitution of Nepal 2015, seven provinces were formed as province 1 , province 2 , province 3 , province 4 , province 5 , province 6 and province 7 . The formation of the provinces was based on the language and caste/ethnic diversity, although there is no majority caste/ethnic population in any of these provinces. These provinces were coded as categories variable: province 1 , province 2 , province 3 , province 4 , province 5 , province 6 and province 7 . We used province 3 as a 'reference category' because Kathmandu, the capital city of Nepal, is in province 3. We also included two factors that we predicted would be structural barriers to accessing vaccines; affordability (money was reported to be as big problem) and accessibility (distance to health facility). Those who responded that money was not a big problem were coded as ' 0 ' and those who responded that money was not a big problem were coded as ' 1 '. Similarly, those who reported distance to healthcare facility was not a big problem were recoded as ' 0 ' and those who responded 'big problem' were coded as ' 1 '.

\section{Data analyses}

The statistical analyses were performed using the software SPSS for Windows (V.25). We first ran descriptive and bivariate statistical analyses. To identify factors that are significantly associated with complete childhood immunisation, we ran multivariate logistic regressions. Variables which were significant in our univariate analyses were included in the multivariate logistic regression analyses. To determine the statistical significance, we used a $p$ value less than 0.05 .
Patient and public involvement statement

Patients and the public were not involved in the research.

\section{RESULTS}

Overall, $79.2 \%$ of the children were fully immunised while $97.7 \%$ of children had received a BCG vaccination, $88.6 \%$ received full doses of polio vaccines, $87.4 \%$ received total doses of DPT vaccines and nearly $91 \%$ of the children had their measles vaccine (table 1 ).

Table 2 presents the descriptive characteristics of the sample and the bivariate association between independent and dependent variables. Fifty-six percent of the children were boys and $44 \%$ were girls. Almost $30 \%$ of the children were from high Hindu caste families, $16.4 \%$ were from the previously untouchable caste, $31.5 \%$ were from indigenous families and $22.3 \%$ were from the Terai caste or were Muslim. Nearly $30 \%$ of mothers never had any formal schooling. Results from bivariate analyses indicated that caste/ethnic affiliation, mother's education, wealth status, ecological region, provinces, number of children under 5 , money to pay to get to a healthcare facility and distance to healthcare facilities were significantly associated with complete childhood immunisation. We also found that only $66.4 \%$ of Terai caste and Muslim children were fully immunised whereas $82.5 \%$ of high Hindu caste children were fully immunised. Similarly, $65.7 \%$ of children who live in province 2 were fully immunised, whereas almost $92 \%$ of children living in province 4 were fully immunised (table 2).

Results from the multivariate analysis showed that children from the previously untouchable caste (OR 0.58 ; CI 0.33 to 0.99 ) and the Terai caste (OR 0.54; CI 0.29 to 0.99 ) were less likely to be fully immunised than children from the high Hindu caste. Similarly, children from the Terai caste were less likely to have had polio and DPT vaccine than children from high Hindu castes. Children living in Hill region were more likely to be fully immunised and more likely to get complete doses of polio vaccines and DPT vaccines than children living in Mountain region. Although statistical significance was weaker, more abundant wealth status was correlated with a child's likelihood of being vaccinated, such as a total dose of polio, a measles vaccine and overall full immunisation. Similarly, children from mothers reporting immediate financial problems (eg, money is a big problem) were less likely to be fully immunised, including a complete dose of DPT and measles, than their counterpart (see table 3$)$.

\section{DISCUSSION}

Article 20 of the United Nations Convention on the Rights of the Child (UNCRH) declares that no child should be left behind or deprived of his or her rights to access healthcare, including the right to be fully immunised. ${ }^{22} \mathrm{In}$ 
Open access

Table 1 Childhood immunisation by the vaccine type

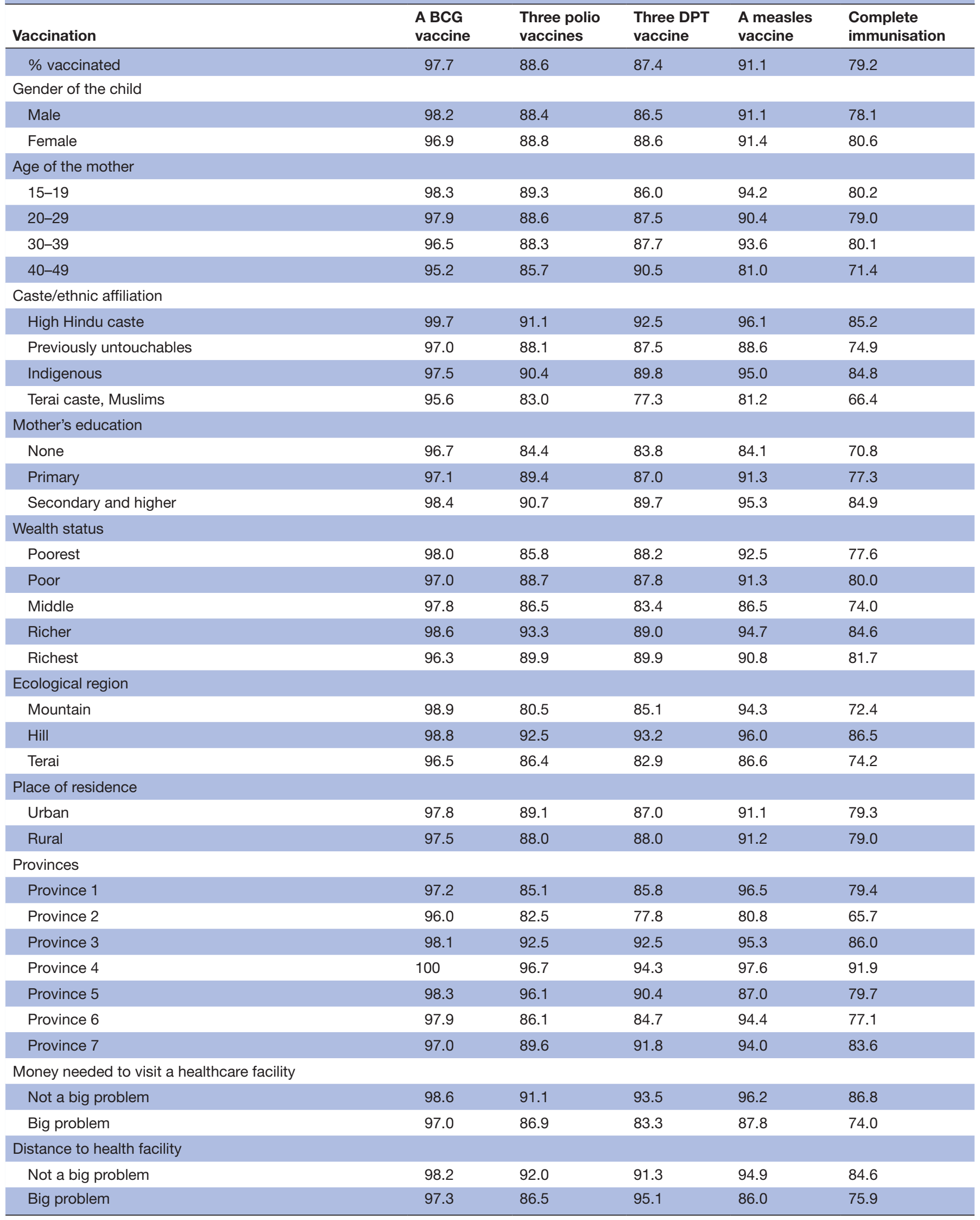

BCG, Bacillus Calmette-Guerin; DPT, diphtheria-tetanus-pertussis. 


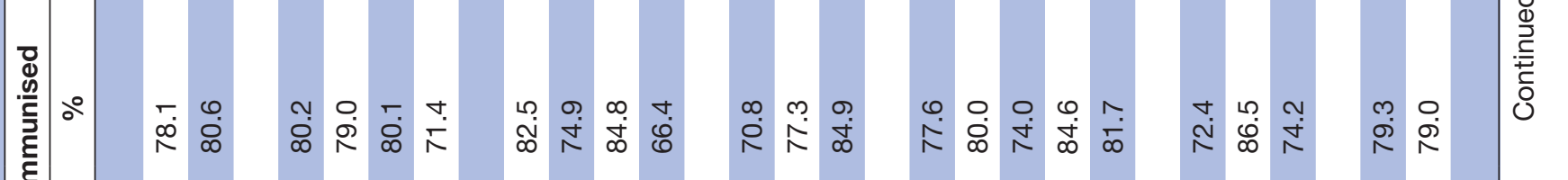
(1).

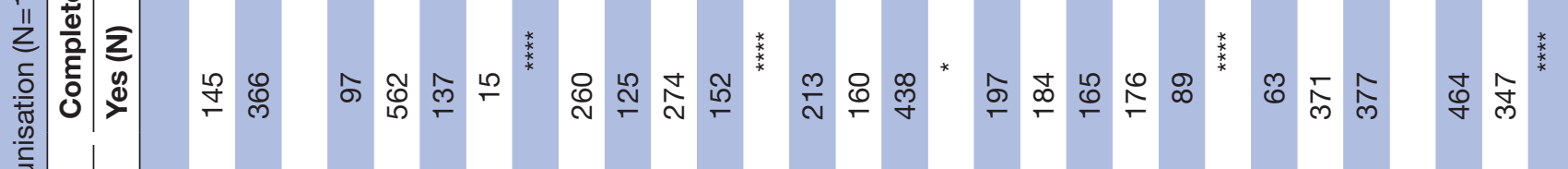

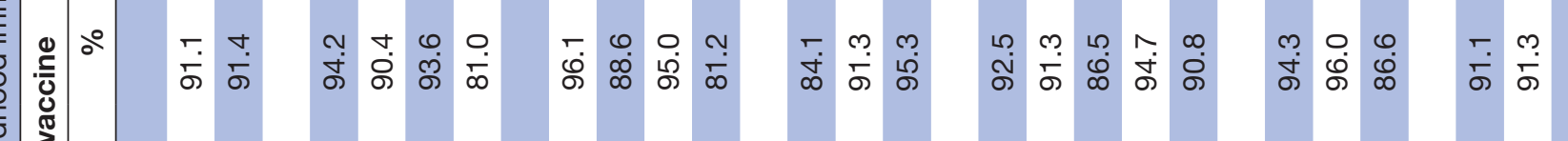

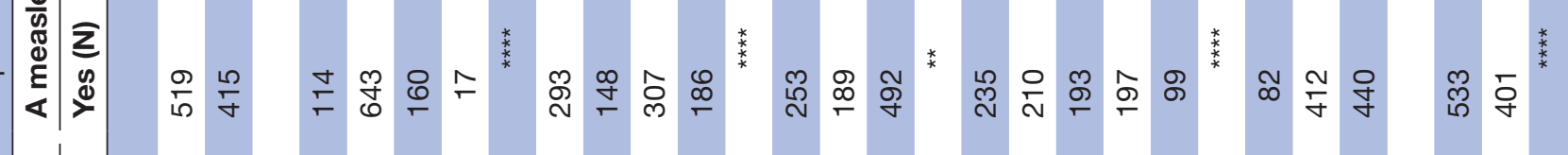
高

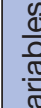




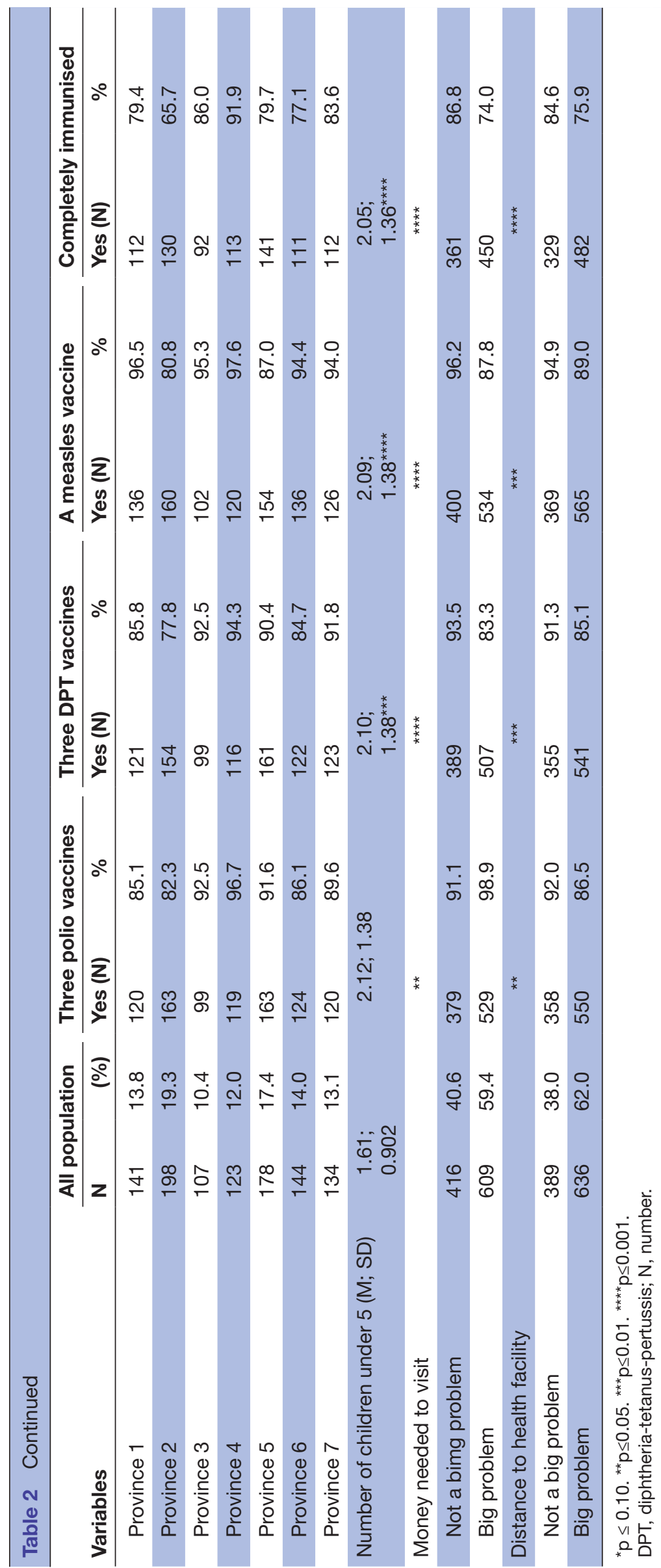

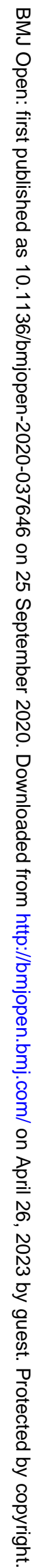




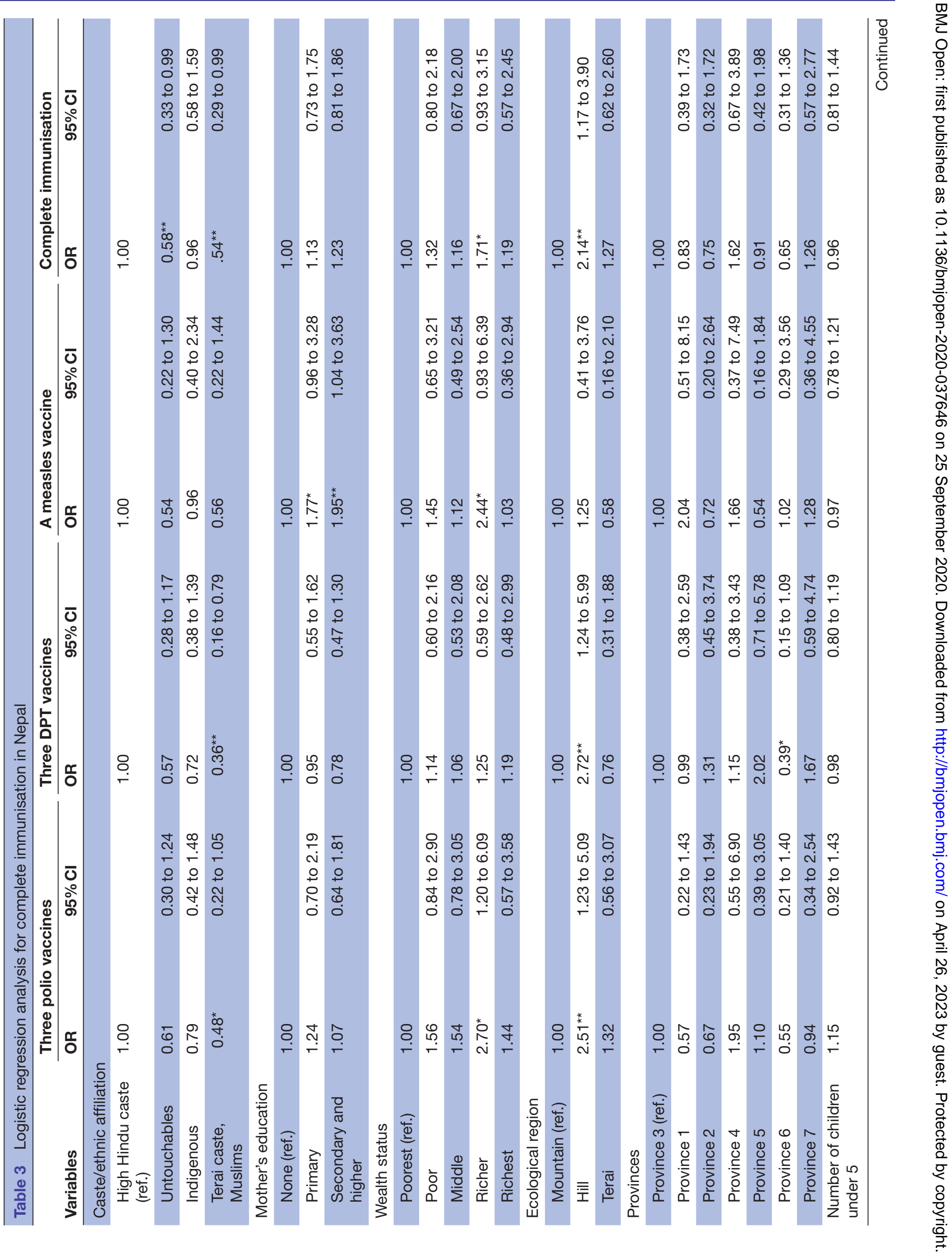




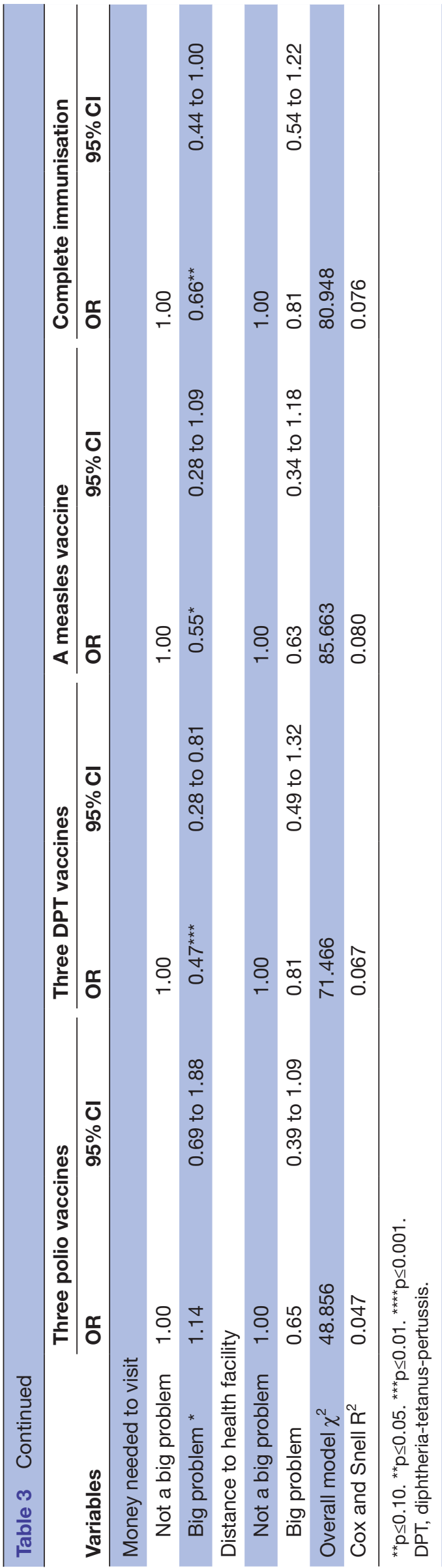

line with the UNCRH, Nepal began offering free vaccines to vaccinate its children fully. Despite the progress on immunisation of 1-year-old children, complete childhood immunisation has still remained a challenge in Nepal. ${ }^{23}$

The government of Nepal has committed to achieve UN SDG 3 and sought to increase the childhood vaccination rates through its National Immunisation Programme by providing childhood immunisation to all sections of the population. In order to ensure that Nepal can successfully implement programmes designed to increase childhood vaccination rates, it is essential to understand who is and who is not being vaccinated. We highlight some of the key findings of this study.

The findings of this analysis are consistent with previous research and indicate that family financial problems (acute poverty; for example, the money to visit health facility) as well as being a member of a low or underprivileged caste all affect the likelihood that a child will or will not be immunised. The fact is that Nepal is one of the lowest income countries in the world with a Human Development Index of 0.58 ranking 147th out of 187 countries with about $35.4 \%$ of people living in absolute poverty (on less than US $\$ 3.19$ per day). ${ }^{24}$ In 2011, the average mortality rate in Nepal for children under 5 was 68 per 1000 , much higher for previously untouchable caste (Dalits), 90 per $1000 .{ }^{16}$ The finding of the study further supports the Nepal's socioeconomic and geographical disparities create challenges to increasing its childhood immunisation rates. Despite access to free vaccines throughout the country, intersection of acute poverty and belonging to socially excluded caste/ethnic groups still makes it less likely to be fully vaccinated by age 2 .

Notwithstanding, the abolishment of the caste system in 1990 in Nepal's Constitution, its legacy is apparent and the caste/ethnic-based social structure and hierarchy is still intact. Previous studies have documented that the caste/ethnicitybased social exclusion is deeply rooted in Nepalese social structure, specifically people belonging to the untouchable caste as well as belonging to Terai caste (including Madeshi and Muslims) face broad-based discrimination and are socially excluded from the power structures in society. ${ }^{17}$ As consequences of such social exclusion, they are more likely to experience other forms of disadvantages such as living in poverty and exposure of domestic violence. ${ }^{25}$ Consistent with this social context, children belonging to previously untouchable and Terai caste are less likely to be fully immunised than other children.

Mothers with at least a secondary education were more likely to vaccinate their children. ${ }^{26}$ This finding is consistent in the case of measles vaccination in Nepal. However, that was not true for other vaccines. The measles vaccine has to be completed between 9 and 12 months, whereas other vaccines are usually done earlier. Likewise, household wealth status itself was not a strong statistically significant predictor for childhood immunisation. However, acute poverty (eg, families which lack the money needed to visit a healthcare facility) is a significant barrier for complete immunisation. This is likely because the government has provided free vaccines in Nepal since the inception of the Expanded Programme on 
Immunisation in 1979. ${ }^{27}$ This suggests that though in many places in Nepal vaccines are readily available in healthcare centres, acute poverty affects some women's ability to access to these healthcare centres. Mothers who reported 'money as a big problem' to visit healthcare facilities were less likely to fully immunise their children. Nepal currently provides some financial incentives to mothers who give birth in hospitals or health centres. We recommend that this programme be expanded to offer financial incentives to mothers who immunise their children in an effort to further reduce financial barriers to immunisation.

We found that there are no gender differences between children who were fully immunised in Nepal. This finding is inconsistent with the previous studies that were conducted in South Asian context, especially India ${ }^{11-13}$ However, there is a sex ratio imbalance in the overall population; $44 \%$ of children were girls and $56 \%$ were boys. This indicates the male preference in Nepalese societies and the possibility of sexselective abortion. ${ }^{28}$ Interestingly, this sex preference does not seem to have influenced childhood immunisation rates in Nepal. Further inquiry is needed to understand why.

We found that children living in the Hill region were more likely to be fully vaccinated than other subpopulations. The people in the Hill region belong to the top and the bottom of the caste system and they brought the tradition of caste-based social structure. Such tradition of social groupings included the Brahmans (priests, teachers and scholars), the Kshatriyas (kings and warriors), the Vaishyas (traders and businesspeople or indigenous people) and the Shudra (untouchables or occupational castes or Dalits). The majority of people who live in the Hill region is from high Hindu caste backgrounds, and this population has a more significant influence on linguistic, sociopolitical and cultural aspects in Nepal. ${ }^{29}$

\section{Recommendations}

The study explored social inequalities in Nepal, such as belonging to the underprivileged caste/ethnic group, living in acute poverty and geographical disparities predicted to impede or facilitate childhood immunisation for Nepalese children. Based on the study findings, we recommend that it is essential to reduce deep-rooted social inequalities in order to effectively deliver essential social and health services, including childhood immunisation. One way to do this is to improve social inclusion and to provide welfare programmes, particularly for socially underprivileged caste/ethnic populations. We also recommend providing financial incentives to families that immunise their children. Such practices would support UN SDG 3, Article 20 of the UNCRH and Rights to Healthcare which is also mandated by Article 35 of the 2015 Nepalese Constitution.

\section{CONCLUSION}

Each country has their own issues that limit access to health and welfare services. In Nepal, we found that children belonging to the underprivileged caste/ethnic groups and those whose mothers reported being in a financial crisis situation (eg, money is a big problem to visit healthcare facility) were the least likely to be fully immunised. We recommend working to reduce deep seated social inequalities in Nepal that are correlated with children being less likely to be vaccinated. Nepal not only needs to do more than legislate to end the caste system (which has been done) but also needs to enforce such legislation. Another way to improve access to childhood vaccines would be to increase educational opportunities for girls. Finally, and perhaps the most easily accomplished, more systematic vaccination programmes such as community-based education and financial incentives to vaccinate children could be designed to specifically target socially excluded children.

Contributors All authors have substantially contributed to this manuscript. IHS designed the manuscript, MSA prepared the dataset and conducted the statistical analysis under the supervision of IHS and EP. MSA prepared the initial draft of the paper. IHS and EP revised the paper and contributed to preparing the final draft for the submission.

Funding The authors have not declared a specific grant for this research from any funding agency in the public, commercial or not-for-profit sectors.

Competing interests None declared.

Patient and public involvement Patients and/or the public were not involved in the design, or conduct, or reporting, or dissemination plans of this research.

Patient consent for publication Not required.

Ethics approval For the 2016 NDHS, ethical approval was obtained from the Nepal Health Research Council, Kathmandu, Nepal and ICF Macro Institutional Review Board, Maryland, USA.

Provenance and peer review Not commissioned; externally peer reviewed. Data availability statement Data are available upon request.

Open access This is an open access article distributed in accordance with the Creative Commons Attribution Non Commercial (CC BY-NC 4.0) license, which permits others to distribute, remix, adapt, build upon this work non-commercially, and license their derivative works on different terms, provided the original work is properly cited, appropriate credit is given, any changes made indicated, and the use is non-commercial. See: http://creativecommons.org/licenses/by-nc/4.0/.

ORCID iD

In Han Song http://orcid.org/0000-0003-0617-3917

\section{REFERENCES}

1 UNICEF, WHO. Progress and challenges with achieving universal immunization coverage, 2019. Available: https://www.who.int/ immunization/monitoring_surveillance/who-immuniz.pdf?ua $=1$

2 Kc A, Nelin V, Raaijmakers H, et al. Increased immunization coverage addresses the equity gap in Nepal. Bull World Health Organ 2017;95:261-9.

3 Bhandari P, Shrestha SS, Ghimire DJ. Sociocultural and geographical disparities in child immunization in Nepal. Asia Pac Popul $J$ 2007;22:43-64.

4 Jamison DT, Breman JG, Measham AR. Disease control priorities in developing countries. The World Bank, 2006.

5 Liu L, Oza S, Hogan D, et al. Global, regional, and national causes of child mortality in 2000-13, with projections to inform post-2015 priorities: an updated systematic analysis. Lancet 2015;385:430-40.

6 Devkota S, Butler C. Caste-ethnic disparity in vaccine use among 0to 5-year-old children in Nepal: a decomposition analysis. Int J Public Health 2016;61:693-9.

7 Devkota S, Panda B. Childhood immunization and access to health care: evidence from Nepal. Asia Pac J Public Health 2016;28:167-77.

8 Joe W. Intersectional inequalities in immunization in India, 1992-93 to 2005-06: a progress assessment. Health Policy Plan 2015;30:407-22.

9 Marmot M. Social determinants of health inequalities. Lancet 2005;365:1099-104. 
10 Pandey S, Lee Hnim. Determinants of child immunization in Nepal: The role of women's empowerment. Health Educ J 2012;71:642-53.

11 Corsi DJ, Bassani DG, Kumar R, et al. Gender inequity and ageappropriate immunization coverage in India from 1992 to 2006. BMC Int Health Hum Rights 2009;9 Suppl 1:S3.

12 Prusty RK, Kumar A. Socioeconomic dynamics of gender disparity in childhood immunization in India, 1992-2006. PLoS One 2014;9:e104598.

13 Singh PK. Trends in child immunization across geographical regions in India: focus on urban-rural and gender differentials. PLoS One 2013;8:e73102.

14 Jheeta M, Newell J. Childhood vaccination in Africa and Asia: the effects of parents' knowledge and attitudes. Bull World Health Organ 2008;86:419.

15 Subhani S, Yaseen R, Khan MA, et al. Impact of mother's education on child immunization: a comparative study of India and Pakistan. $J$ financ econ 2015;3:51-4.

16 Ministry of Health and Population (MOHP) [Nepal], New ERA, ICF International Inc. Nepal demographic and health survey 2011. Kathmandu, Nepal: Ministry of Health and Population, New ERA, and ICF International, Calverton, Maryland, 2012.

17 Dahal DR. The'Madhsi'People: issues and challenges of democracy in the Nepal Terai.Local democracy in South Asia.Microprocesses of democratization in Nepal and its neighbours, 2008: 1-128.

18 Anand S, Bärnighausen T. Health workers and vaccination coverage in developing countries: an econometric analysis. Lancet 2007;369:1277-85.

19 World Health Organization. Immunization in practice: a guide for health workers who give vaccines. module l: vaccines and when to give them. Geneva: Department of Vaccines and Biologicals, World Health Organization, 1984

20 Sarker AR, Akram R, Ali N, et al. Coverage and determinants of full immunization: vaccination coverage among Senegalese children. Medicina 2019;55:480.
21 Pradhan R, Wynter K, Fisher J. Factors associated with pregnancy among married adolescents in Nepal: secondary analysis of the National demographic and health surveys from 2001 to 2011. Int J Environ Res Public Health 2018;15:229.

22 Office of the United Nations High Commissioner for Human Rights. Convention on the rights of the child, adopted and opened for signature, ratification and accession by general assembly resolution 44/25 of 20 November 1989 entry into force 2 September 1990, in accordance with article 49

23 World Health Organization. World immunization week in Nepal: an anniversary of remembrance, 2016. https://www.who.int/newsroom/feature-stories/detail/world-immunization-week-in-nepal-ananniversary-of-remembrance

24 United National Development Reports. Human development report 2019, 2019. Available: http://hdr.undp.org/en

25 Atteraya MS, Gnawali S, Song IH. Factors associated with intimate partner violence against married women in Nepal. J Interpers Violence 2015;30:1226-46.

26 Tam WWS, Chan J, Lo KKH, et al. Parental attitudes and factors associated with varicella vaccination in preschool and schoolchildren in Hong Kong: a cross-sectional study. Medicine 2015;94:e1519.

27 World Health Organization(WHO). The expanded programme on immunization,, 2013. Available: http://www.who.int/immunization/ programmes systems/supply chain/benefits of immunization/en/

28 Lamichhane P, Harken T, Puri M, et al. Sex-Selective abortion in Nepal: a qualitative study of health workers' perspectives. Womens Health Issues 2011;21:S37-41.

29 Bennett L, Dahal DR. Caste, ethnic, and regional identity in Nepal: further analysis of the $2006 \mathrm{Nepal}$ demographic and health survey. Population Division, Ministry of Health and Population, Government of Nepal, 2008. 